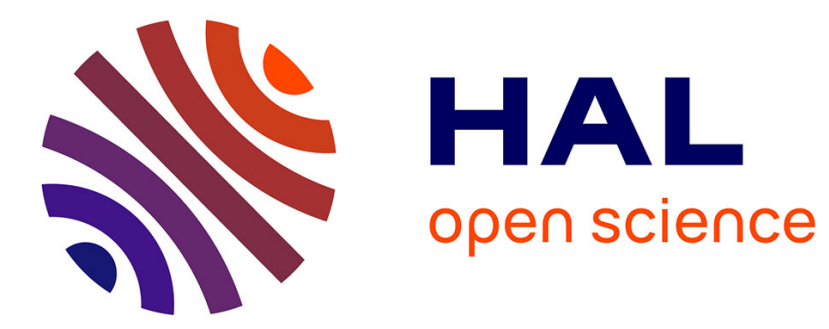

\title{
INFLUENCE OF EXTRUSION PROCESS PARAMETERS ON THE MECHANICAL PROPERTIES OF Al-Li-EXTRUSIONS
}

\author{
G. Tempus, G. Scharf, W. Calles
}

\section{> To cite this version:}

G. Tempus, G. Scharf, W. Calles. INFLUENCE OF EXTRUSION PROCESS PARAMETERS ON THE MECHANICAL PROPERTIES OF Al-Li-EXTRUSIONS. Journal de Physique Colloques, 1987, 48 (C3), pp.C3-187-C3-193. 10.1051/jphyscol:1987322 • jpa-00226552

HAL Id: jpa-00226552

https://hal.science/jpa-00226552

Submitted on 1 Jan 1987

HAL is a multi-disciplinary open access archive for the deposit and dissemination of scientific research documents, whether they are published or not. The documents may come from teaching and research institutions in France or abroad, or from public or private research centers.
L'archive ouverte pluridisciplinaire HAL, est destinée au dépôt et à la diffusion de documents scientifiques de niveau recherche, publiés ou non, émanant des établissements d'enseignement et de recherche français ou étrangers, des laboratoires publics ou privés. 


\title{
INELUENCE OF EXTRUSION PROCESS PARAMETERS ON THE MECHANICAL PROPERTIES OF Al-Li-EXTRUSIONS
}

\author{
G. TEMPUS, G. SCHARF and W. CALLES \\ Vereinigte Aluminium-Werke $A G$, Leichtmetall-Forschungsinstitut, \\ B.P. 2468, D-5300 Bonn, F.R.G.
}

\begin{abstract}
The influence of the extrusion process parameters and TMT on the mechanical properties of different Lital A (8090)-extrusions was investigated. Strength was shown to be influenced less by extrusion temperature and ratio than by the extrusion aspect ratio (width/thickness) determining texture. With increasing extrusion aspect ratio the strength declines considerably. Depending on the homogeneity of slip distribution the strength decrease can be calculated with excellent accuracy by the SACHS- or the TAYLOR-model on the bas is of a quantitative texture analysis.
\end{abstract}

\section{INTRODUCTION}

For the production of high quality $A 1-L i$ semiproducts ready for service it is essential to get knowledge of the influence of the production conditions on the properties of the semiproduct. As there are little publications especially for extrusions $[1,2]$, the purpose of this investigation is to determine the influence of the extrusion process parameters on the tensile properties of differently shaped extrusions. As the strength of Al-Li sheet and plate material is known to have a stronger susceptability towards texture [3-6], this topic is a point of special interest in this investigation.

\section{EXPERIMENTAL PROCEDURE}

The extrusion billets $(\emptyset 77 \times 200 \mathrm{~mm})$ were machined from rectangular. DC cast bars $(300 \times 900 \times 2500 \mathrm{~mm})$. The chemical composition of the used Lital A-alloy (8090) is given in Tab. 1 .

\begin{tabular}{cccccccccc}
$\mathrm{Li}$ & $\mathrm{Cu}$ & $\mathrm{Mg}$ & $\mathrm{Zr}$ & $\mathrm{Si}$ & $\mathrm{Fe}$ & $\mathrm{Mn}$ & $\mathrm{Cr}$ & $\mathrm{Zn}$ & $\mathrm{Ti}$ \\
\hline 2.45 & 1.08 & 0.73 & 0.1 & 0.03 & 0.04 & 0.001 & 0.001 & 0.02 & 0.02
\end{tabular}

Tab. 1: Chemical composition of the Lital A alloy investigated

The billets were homogenised for $24 \mathrm{~h}$ at $550^{\circ} \mathrm{C}$ in air and directly extruded on a $3.15 \mathrm{MN}$-press with a $80 \mathrm{~mm}$ dia. container. Within $2 \mathrm{~min}$. the billets were heated to the extrusion temperatures of $400^{\circ} \mathrm{C}$ or $450^{\circ} \mathrm{C}$, which were always equal to those of the container. Circular rods $(\emptyset 16 \mathrm{~mm})$, and different flat shapes were extruded (exit speed $2 \mathrm{~m} / \mathrm{min}$.). All extrudates were solution treated for $30 \mathrm{~min}$. at $535^{\circ} \mathrm{C}$, quenched in water $\left(20^{\circ} \mathrm{C}\right)$ and then stretched (2\%) immediately: After pre-aging $\left(5 \mathrm{~d}, 20^{\circ} \mathrm{C}\right)$ the extrusions were aged at $185^{\circ} \mathrm{C}$. Additionally the circular rod was aged without preceding stretch. The tensile properties were determined in extrusion direction.

The texture measurements were carried out on a futly automatic and computer-controlled texture goniometer [7]. For each specimen four incomplete different pole figures $\{111\},\{200\},\{220\},\{113\}$ up to a maximum ti\}ting angle of $85^{\circ}$ were 
measured, from which the three-dimensional orientation distribution functions (ODF) were calculated [8]. By the means of isotropic Gauß-type distribution functions the ODF were separated in the single components of texture and quantitatively evaluated [9].

\section{RESULTS}

3.1 Influence of Stretch on the Artificial Aging Behaviour

Fig. 1 shows the dependence of the mechanical properties of the circular rods from aging time at $185^{\circ} \mathrm{C}$ with and without stretch (extrusion temperature $450^{\circ} \mathrm{C}$ ). At the beginning of aging the strength values without stretch are higher than those for the stretched condition. With increasing aging time the strength for the unstretched condition reaches a plateau followed by the peak strength. By stretching, however, the strength is continuously increasing to its peak. Maximum strength is achieved after an aging time of $30 \mathrm{~h}$ for each treatment. The yield strength $R_{p 0} 2$ is higher by $25 \mathrm{MPa}$ and tensile 0.2 strength $R_{\mathrm{m}}$ by $10 \mathrm{MPa}$ due to stretching. At the beginning of aging the elongation values $A_{6}$ drop for both conditions. Then for the unstretched rod the elongation remains nearly constant and then increases with

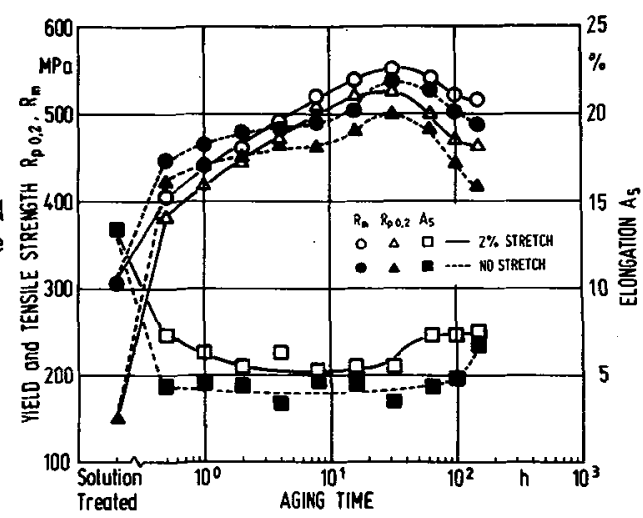

Fig. 1: Age hardening curve $\left(185^{\circ} \mathrm{C}\right)$ of the circular rod overaging. For the stretched condition the elongation exhibits a slight minimum and increases just before the aging peak. Stretching always results in slightly higher values of both strength and elongation. Therefore in the further investigation, all extrusions were stretched before aging.

\subsection{Influence of Extrusion Parameters and Shape on the Tensile Properties}

The strength of different shapes (circular and flat) extruded at $450^{\circ} \mathrm{C}$ and aged for $30 \mathrm{~h}$ at $185^{\circ} \mathrm{C}$ does not systematically depend on the extrusion ratio $R$ (Fig.2). For nearly equal extrusion ratios in the range from $1: 22.3$ to $1: 25.8$ e.g.

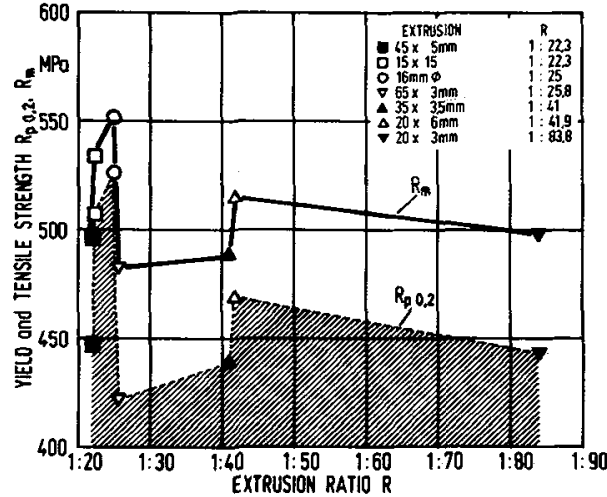

Fig. 2: Influence of extrusion ratio $R$ on strength $R_{p 0.2}, R_{m}$

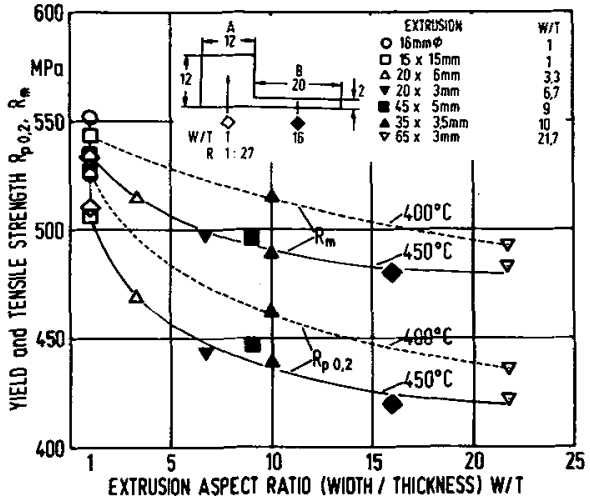

Fig. 3: Strength $R_{p 0.2}, R_{m}$ vs. extrusion aspect ratio $W / T$ 
there are considerable differences in strength. The shapes also differ in the extrusion aspect ratio $W / T$ of width $W$ to thickness $T$. From the minimum $W / T$-ratio of 1 (axisymmetric shapes) (Fig. 3) the strength strongly drops and is still being reduced for $W / T$-ratios greater than 10 . This reduction is approximateiy by. two times greater for the yield than for the tensile strength. Yield strength differs most between the circular rod $(W / T=1)$ and the $65 \times 3 \mathrm{~mm}$ flat shape $(W / T=21.7)$. In Fig. 3 the strength values of three shapes extruded at $400^{\circ} \mathrm{C}$ are given additionally. On a level $10-26 \mathrm{MPa}$ higher than by extrusion at $450^{\circ} \mathrm{C}$ they show the same $W / T$-dependency. In order to verify the influence of the W/T-ratio at one extrusion the $L$-shape shown in Fig. 3 was extruded at $450^{\circ} \mathrm{C}$. It can be divided in section $A$ (thickness $12 \mathrm{~mm}, W / T=1$ ) and section $B$ (thickness $2 \mathrm{~mm}$, $W / T=16$, if the entire width of the shape is considered). The strength values of the sections $A$ and $B$ fit very good to the dependency of Fig. 3. The elongation values (Fig. 4) are nearly independent from the W/T-ratio and do not differ significantly for the

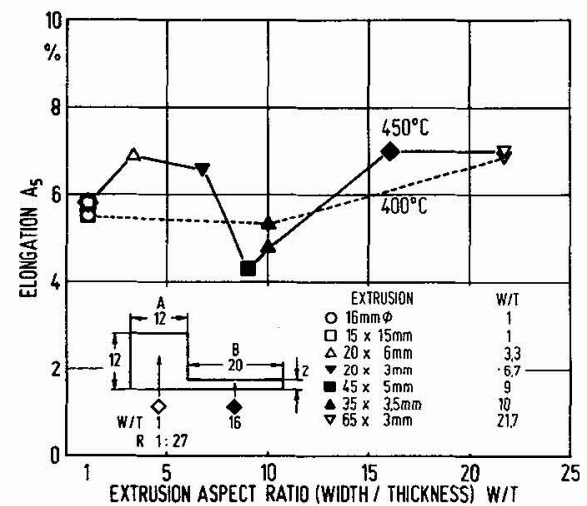

Fig. 4: Elongation $A_{5}$ vs. extru-

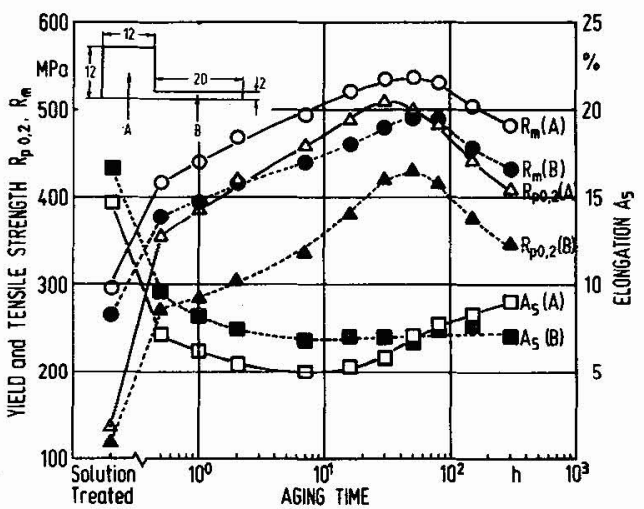

Fig. 5: Age hardening curve of section $A$ and $B$ ( $L$-shape)

two extrusion temperatures. The influence of the state of precipitation on the $W / T$-dependency was determined by the age hardening curves of the sections $A$ and $B$ (Fig. 5). As expected from the same $W / T-$ ratio of 1 , similar curves for strength and elongation are observed for section $A$ and the circular rod (Fig. 1). In section $B$, however, the peak strength is reached $20 \mathrm{~h}$ later and the strength is always lower. There are also considerable differences in the elongation curves.

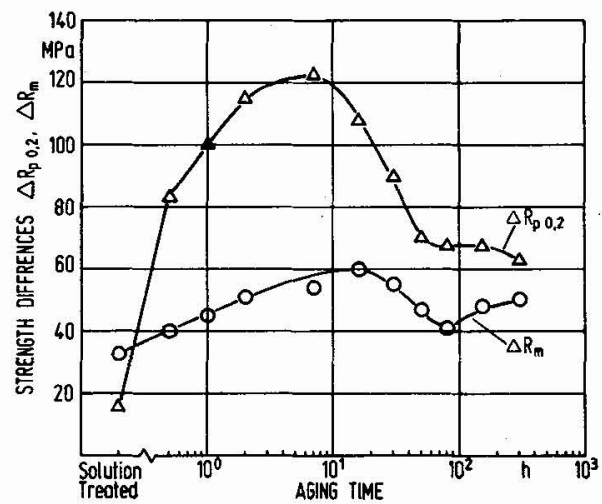

Fig. 6: Strength difference between section $A$ and $B$ vs. aging time

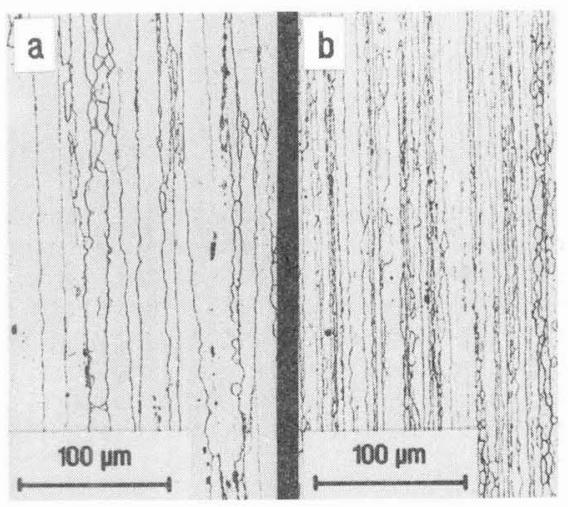

Fig. 7: Grain structure of section $A(a)$ and $B(b)$ 
At the begin of aging the elongation declines for the two sections. For section $B$ it remains nearly constant up to the overaged condition. Section $A$ exhibits lower elongation values with a minimum after $8 \mathrm{~h}$. Having reached its peak aged condition the elongation is even significantly greater than that of section $B$.

The difference of yield strength $\Delta R_{00.2}$ and tensile strength $\Delta R_{m}$ between section $A$ and $B$ changes with aging time ( $F i B_{0.2} 6$ ). After quenching and ${ }^{m}$ in the overaged

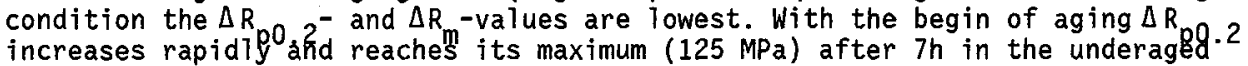
condition. The differences in tensile strength $\Delta R_{p}$ are approximately half of those in yield strength. Compared with the curve por $\Delta R_{p 0.2}$ the maximum is less pronounced and is reached after a longer aging time $\mathrm{p}_{0.2}(16 \mathrm{~h})$.

\subsection{Influence of Microstructure}

The microstructures of section $A$ and $B\left(30 \mathrm{~h} 185^{\circ} \mathrm{C}\right)$ were examined by light and TEM microscopy in order to determine the reason for the strength differences. In the centre of section A and B (Fig. 7) there is an as-extruded microstructure with pancake-shaped grains in section $B$ due to the greater $W / T$-ratio. At the original grain boundaries a fine recrystallisation has started with the recrystallised volume fraction slightly greater in section $B$. The results of the TEM-examination show the subgrains to be equal in structure and size. There are also no differences in the state of precipitation. The flatter grains in part $B$ and the higher degree of recrystallisation are unlikely to cause the remarkable difference in strength.

\subsection{Influence of Texture}

The $\{111\}$-pole figures taken from the centre of section $A$ and $B$ differ considerably (Fig. 8). According to its axisymmetric deformation section A shows a pronounced $\langle 111\rangle+\langle 100\rangle$ double fibre texture.
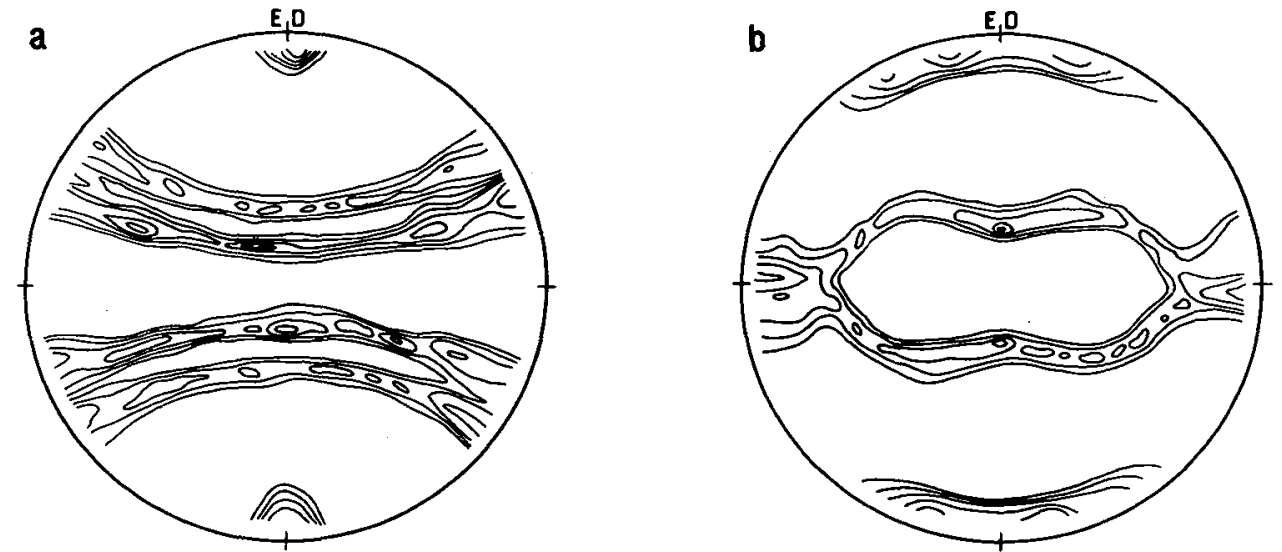

Fig. 8: $\{111\}$-pole figures of section $A(a)$ and $B$ (b)

Due to the predominantiy plane deformation the texture of section $B$ is similar to that achieved by rolling. The volume fractions of each texture component and the background were determined from the ODF's (Tab. 2). The double fibre texture (section $A$ ) is composed of $75 \%$ in $\langle 111\rangle$ direction and of $22 \%$ in $\langle 100\rangle$ direction. Irrespective of slight deviations from the given ideal orientation, in section $B$ the three typical rolling textures $S$, Bs and $\mathrm{Cu}$ predominate with a total amount of $65.9 \%$. For each texture component the orientation factors Ms and Mt resp. were calculated, which relate yield stress $\sigma_{y}$ and critical resolved shear stress $\tau_{c}$ :

$$
\sigma_{y}=M s, t \cdot \tau_{c}
$$


Ms is the factor for the SACHS-model (inverse SCHMID-factor $1 / \mathrm{m}$ ) and Mt the TAYLOR-factor. According to the SACHS-model [10] plastic deformation occurs as single slip in the $\{111\}\langle 110\rangle$ slip system with the minimum factor Ms, i.e. the maximum SCHMID-factor $m$. The TAYLOR- model [11], however, is valid for multi-slip in at least five independent $\{111\}\langle 110\rangle$ slip systems. In Tab. 2 the factors Ms

\begin{tabular}{|c|c|c|c|c|c|c|c|c|c|}
\hline$\langle u v w\rangle$ & $\begin{array}{l}\text { Section } \\
\text { Mi\% }\end{array}$ & $\begin{array}{l}A \\
M t\end{array}$ & Ms & $\begin{aligned} & \mathrm{Se} \\
& \text { Component }\end{aligned}$ & $\begin{array}{l}\text { ction B } \\
\{\text { hk } 1\}\end{array}$ & $\langle u v w\rangle$ & Mi\% & Mt & Ms \\
\hline \multirow[t]{2}{*}{$\begin{array}{l}\langle 111\rangle \\
\langle 100\rangle \\
\text { Background }\end{array}$} & $\begin{array}{r}75 \\
22 \\
3\end{array}$ & $\begin{array}{l}3.67 \\
2.45 \\
3.07\end{array}$ & $\begin{array}{l}3.67 \\
2.45 \\
2.24\end{array}$ & $\begin{array}{l}\text { S } \\
\text { Bs } \\
\text { Cu } \\
\text { Goss/Bs } \\
- \\
-\end{array}$ & $\begin{array}{l}\{123\} \\
\{011\} \\
\{112\} \\
\{011\} \\
\{138\} \\
\{111\}\end{array}$ & $\begin{array}{l}\langle 634\rangle \\
\langle 211\rangle \\
\langle 111\rangle \\
\langle 511\rangle \\
\langle 751\rangle \\
\langle 112\rangle\end{array}$ & $\begin{array}{r}33 \\
18.7 \\
14.2 \\
5.4 \\
3.3 \\
2.9\end{array}$ & $\begin{array}{l}3.19 \\
3.07 \\
3.62 \\
2.34 \\
2.55 \\
3.18\end{array}$ & $\begin{array}{l}2.48 \\
2.45 \\
3.05 \\
2.21 \\
2.12 \\
2.54\end{array}$ \\
\hline & & & & $\begin{array}{l}\text { Cube }_{\mathrm{RD}} \\
\text { Background }\end{array}$ & $\{025\}$ & $\langle 100\rangle$ & $\begin{array}{r}2.1 \\
20.4\end{array}$ & $\begin{array}{l}2.45 \\
3.07\end{array}$ & $\begin{array}{l}2.45 \\
2.24\end{array}$ \\
\hline
\end{tabular}

Mean Value

\begin{tabular}{lllll}
$\bar{M} \mathrm{t}, \overline{\mathrm{M} s}$ & 3.38 & 3.36 & 3.12 & 2.48 \\
\hline
\end{tabular}

Tab. 2: Volume fraction Mi, TAYLOR-factors Mt and SACHS-factors Ms for the texture components.

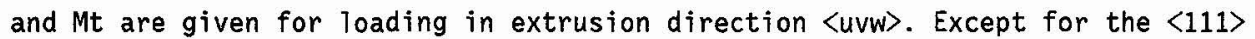
and $\langle 100\rangle$ orientations the Mt-factors are greater than the Ms-factors, because in the case of multi-slip less favoured slip systems must be active to maintain compatibility at the grain boundaries. The Mt and Ms factors are equal for the $\langle 111\rangle$ and $\langle 100\rangle$ orientations, because 6 and 8 slip systems resp. have the same Ms-factor, thus sufficient equivalent slip systems being active for the validity of the TAYLOR-mode1. The mean orientation factors $\bar{M} s$ and $\bar{M} t$-balanced with the volume fraction- are nearly equal for section $A$. In section $B \bar{M}_{s}$ and $\bar{M} t$ differ considerably and they are lower than in section $A$, especially for the SACHS-model. The higher Mt and $\bar{M} s$ values of section $A$ are due to the high volume fraction $(75 \%)$ of $\langle 111\rangle$ orientations with the highest Mt and Ms factors at all. For the same critical resolved shear stress in both sections the difference of the yield strength $\Delta R_{p 0.2}$ related to the yield strength of section $A\left[R_{p 0.2}(A)\right]$ can be

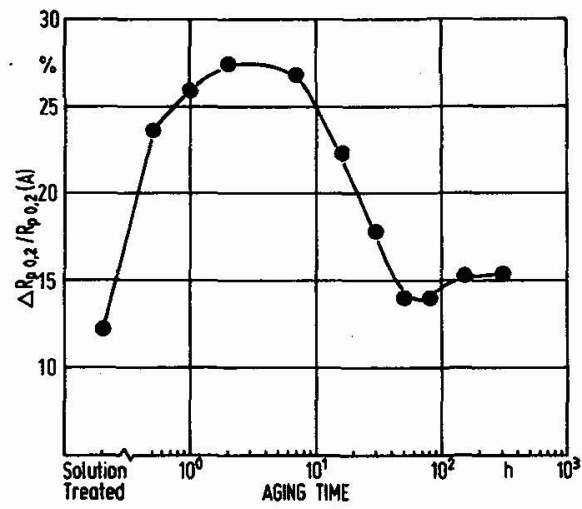

Fig. 9: Strength difference related to " $A$ " vs. aging time
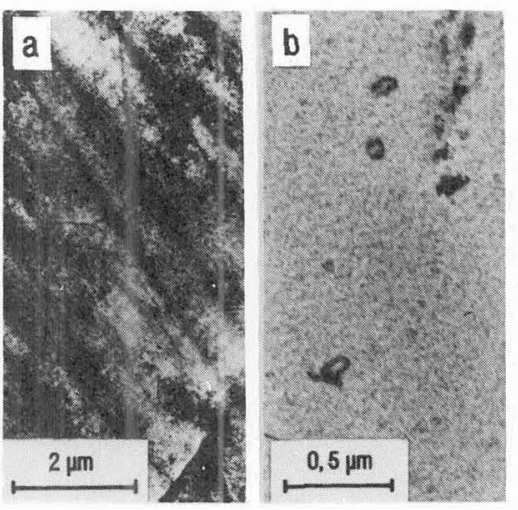

Fig. 10: Slip distribution (a) and precipitation (b) of section $B\left(2 \mathrm{~h} 185^{\circ} \mathrm{C}\right)$ 
calculated from $\bar{M} s$ and $\bar{M} t$ with eqn. (1):

$$
\begin{aligned}
\text { SACHS: } \Delta R_{\mathrm{p} 0.2} / R_{\mathrm{p} 0.2}(\mathrm{~A})=26.2 \% \\
\text { TAYLOR: } \Delta R_{\mathrm{p} 0.2} / R_{\mathrm{p} 0.2}(\mathrm{~A})=7.7 \%
\end{aligned}
$$

These models describe extreme conditions with the SACHS-model as the upper and the TAYLOR-model as the lower limit for the relative difference in yield strength Principaliy the relative strength difference (Fig. 9) shows the same dependency from aging time as the mere strength difference $\Delta R_{p 0.2}$.

In the underaged condition ( $2 \mathrm{~h}$ aging time) the maximum of $27 \%$ is achieved. After quenching or overaging the values are lowest $(12 \%, 15 \%$ resp.).
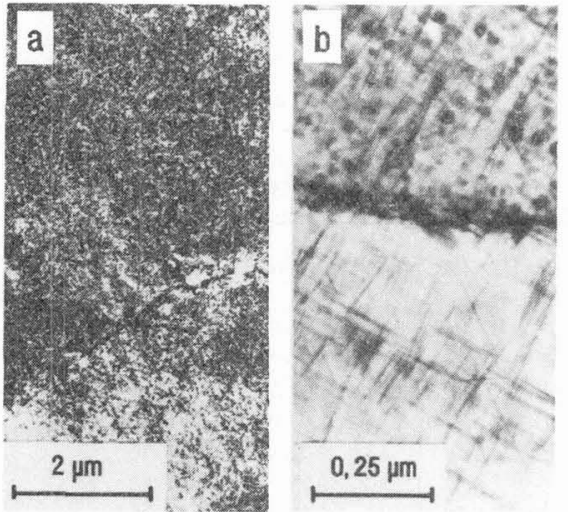

Fig. 11: Slip distribution (a) and precipitation (b) of section $B\left(150 \mathrm{~h} 185^{\circ} \mathrm{C}\right)$

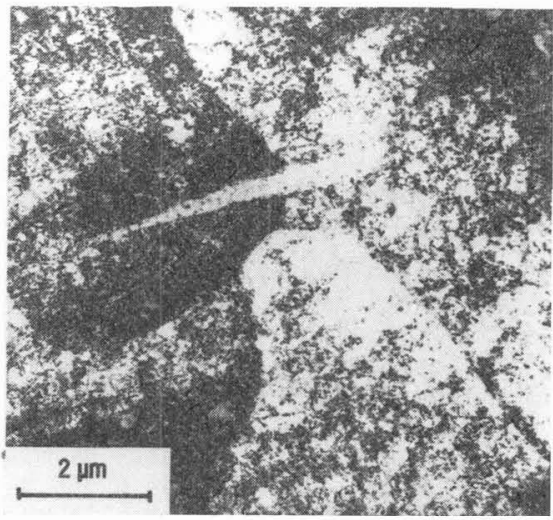

Fig. 12.: Slip distribution of section B (solution treated)

\section{DISCUSSION}

The applicability of either the SACHS- or the TAYLOR-model depends on the predominant slip-mode, which was determined by TEM-analysis of deformed and not deformed sections of the failed tensile specimens (section B).

For the underaged condition $\left(2 \mathrm{~h} 185^{\circ} \mathrm{C}\right)$ slip occurs on single, very pronounced slip bands (Fig. 10a). This inhomogeneous slip distribution is attributed to the spherical, ordered and coherent $\delta^{\prime}\left(A l_{3}{ }^{L} i\right)$ - precipitates (Fig. 10b) easily shearable by dislocations. Once slip in the system with the lowest SACHS-factor has started and cut $\delta$ '-precipitates, this primary slip plane is weakened and further slip is being concentrated on it leading to the observed formation of slip bands [12]. Therefore the relative strength difference in this condition must be calculated by SACHS, which is clearly confirmed by the experiment. After overaging $\left(150 \mathrm{~h} 185^{\circ} \mathrm{C}\right.$ ) the slip distribution is completely homogeneous (Fig. 11a) due to the partiy coherent $S^{\prime}\left(\mathrm{Al}_{2} \mathrm{CuMg}\right)$ Taths besides $\delta$ '-precipitates acting as obstacles to dislocation movement (Fig. 11b). They are bypassed on other (secondary) slip systems with the necessity of multi-slip $[4,13]$.

After quenching slip is also homogeneous (Fig. 12), as the $\delta$-precipitates are too small to be detected and to cause inhomogeneous s7ip [14]. The homogeneous slip is obviously caused by multi-slip. For the quenched and the overaged condition the low relative difference in strength therefore agrees well with the calculation according to the TAYLOR-model. 


\section{CONCLUSIONS}

Compared with extrusion temperature and ratio the strength of Lital A-shapes strongly depends on the extrusion aspect ratio (width/thickness) $W / T$ which

- changes texture

- reduces strength with shapes getting flatter (increasing $W / T$ )

- brings about a strength difference between axisymmetric and flat shapes, which is great at the begin of aging and low after quenching and in the overaged condition.

As the texture-strength relationship is described by the SACHS-model for single slip and by TAYLOR for multi-slip, the strength difference can be calculated on the basis of a quantitative texture analysis with good agreement

- by SACHS for the inhomogeneous slip distribution at the begin of aging

- by TAYLOR for the homogeneous slip distribution after quenching and in the overaged condition.

\section{ACKNOWLEDGEMENTS}

This work was sponsored by the BMFT. The texture analysis by J. Hirsch (Institut für Metallkunde, RWTH Aachen) is gratefully acknowledged.

\section{REFERENCES}

[1] N.C. Parson and T. Sheppard in: "Aluminium-Lithium Alloys II", ed.: T.H. Sanders, Jr. and E.A. Starke, TMS-AIME, Warrendale, PA (1984) 53.

[ 2] N.C. Parson and T. Sheppard in: "Aluminium-Lithium Alloys III",ed.: C.Baker et al., The Institute of Metals, London (1986) 222.

[ 3] M. Peters, K. Welpman and T.H. Sanders, Jr., Proc. 3rd Conf. of E-MRS on Advanced Materials R \& D for Transport, ed.: R.J.H. Wanhill et a1., Les éditions de physique, Les $U 1$ is (1986) 63.

[ 4] P.J. Gregson and H.M. Flower, Acta Metall, 33 (1985) 527.

[ 5] M. Peters, J. Eschweiler and K. Welpmann, Scripta Met., 20 (1986) 259.

[6] S. Fox, D.S. Mc Darmaid and H.M. Flower, Conf. Aluminium Technology 1986, The Institute of Metals, London (1986) 72.1.

[7] J. Hirsch, G. Burmeister, L. Hoenen and K. Lücke in: "Experimental Techniques of Texture AnaTysis", ed.: H.J. Bunge, DGM-Verlag (1986) 63.

[ 8] H.J. Bunge "Mathematische Methoden der Texturanalyse" Akademie Verlag Berlin (1969).

[9] J. Hirsch and K. Lücke in: "Theoretical Techniques of Texture Analysis",ed.: H.J. Bunge, DGM-Verlag (1987).

[10] E. Sachs, $Z$. Verein Deutsch. Ing. 72 (1928) 734.

[11] G.I. Taylor, J. Inst. Met. 62 (1938) 307.

[12] K. Welpmann, M. Peters, T.H. Sanders, Jr., ATuminium 60 (1984) 735 and 846.

[13] W.S. Mi 1 ler, M.P. Thomas, D.J. Lloyd and D. Creber, Mater. Sci. and Techn. 2 (1986) 1210 .

[14] K. V.- Jata and E.A. Starke, Jr., Metal1. Trans. A. 17A (1986) 1011. 